\title{
SYNTHESIS OF SOME NOVEL PYRAZOLE DERIVATIVES AND EVALUATION OF THEIR PURIFICATION OF CHROMATOGRAPHY IN THIN-LAYER CHROMATOGRAPHY
}

\begin{abstract}
SWAPNA B ${ }^{1}$, VIJEY AANANDHI $\mathbf{M}^{2 *}$
${ }^{1}$ Department of Pharmaceutical Chemistry and Analysis, School of Pharmaceutical Sciences, Vels Institute of Science Technology and Advanced Studies, Chennai, Tamil Nadu, India. ${ }^{2}$ Department of Pharmaceutical Chemistry and Analysis, School of Pharmaceutical Sciences, Vels Institute of Science Technology and Advanced Studies, Chennai, Tamil Nadu, India. Email: hodpchemistry@velsuniv.ac.in
\end{abstract}

Received: 10 October 2018, Revised and Accepted: 11 December 2018

ABSTRACT

Objective: The main objective of the study is to synthesis some novel pyrimidine scaffold which has wide range of properties of biological activities.

Methods: Synthesis of different pyrazole derivatives compounds identification and characterization (M.P, solubility, Rf values, and spectral studies). The present work was characterized by infrared, nuclear magnetic resonance, and mass spectral analysis pharmacological evaluation.

Results: Identification and characterization (M.P, solubility, Rf values and spectral studies) are carried out.

Keywords: M.P, Solubility, Rf values, Spectral studies.

(C) 2018 The Authors. Published by Innovare Academic Sciences Pvt Ltd. This is an open access article under the CC BY license (http://creativecommons. org/licenses/by/4. 0/) DOI: http://dx.doi.org/10.22159/ajpcr.2018.v11s4.31678

\section{INTRODUCTION}

Pyrazole derivatives play an important role in the "field of medicinal chemistry due to a wide range of biological" outcomes "exhibited by them" [1]. The uses "of" pyrazole derivatives in clinical medicines are well documented, due to their potent therapeutic values in NSAID, central nervous system, and microbial diseases [2,3]. "Pyrazole refers to the class of simple aromatic ring organic compounds of the heterocyclic" compounds "characterized by a five-membered ring structure composed of" two nitrogen "atoms" in adjacent positions with three carbon atoms "and to the unsubstituted parent compound" [4]. They are "so composed and having pharmacological effects, they are classified as alkaloids," though the availability is very rare in nature. Heterocyclic compounds play an important role in medicinal chemistry for healthcare system. Most frequently encountered heterocyclic molecule in medicinal chemistry is quinazolinone and pyrazole having wide application [5]. Pyrazole derivatives are with good "diverse biological activities such as" analgesic, "antihyperglycemic," antipyretic, "antiinflammatory, sedative-hypnotic activity, cyclooxygenase-2 (Cox-2) inhibitors, interleukin-1 synthesis inhibitors," and antibacterial. Pyrazole was first defined by "LUDWIG KNORR" "in 1883" [6]. "The simple unsaturated compound containing two nitrogen and three carbon atoms in the ring, with the nitrogen atoms" in adjacent positions, "is known as pyrazole." Pyrazoline and pyrazolidine are the reduction products, with five atoms as a ring structure. Several pyrazoline derivatives are used in medicine. Many of the medicinal derivatives are with 5-pyrazolone and 3,5-pyrazolidindione. "Pyrazole is a colorless solid" and "melting point $70^{\circ} \mathrm{C}$ " [7]. This "high value" "is due to intermolecular hydrogen bonding which results in a" dimmer. "Pyrazole" exists as "a tautomeric substance" which "cannot be demonstrated in pyrazole itself, but it can be inferred by the pyrazole derivatives." Pyrazoline derivatives occupy a major role in "medicinal chemistry due to a wide range of biological activities exhibited by them" "Cox, also known as prostaglandin H (PGH) synthase, is a key enzyme involved in the biosynthetic cascade of prostanoids that result in the formation of prostaglandins, prostacyclins, and thromboxanes from polyunsaturated fatty acid." "Cox catalyzes the conversion of arachidonic acid into an intermediate $\mathrm{PGH}_{2}$, a precursor of variety of biologically important prostanoids" [8-10]

\section{EXPERIMENTAL}

Step-I: Ethoxymethylene malononitrile

Malononitrile (5.2 g, $80 \mathrm{mmol})$, triethyl orthoformate $(13.2 \mathrm{ml}, 80 \mathrm{mmol})$, and acetic anhydride $(20.0 \mathrm{ml}, 20 \mathrm{mmol})$ were taken in a round bottom flask fitted with a reflux condenser and calcium guard tube and refluxed for $12 \mathrm{~h}$ at $110^{\circ} \mathrm{C}$. The excess acetic anhydride was distilled off from the reaction medium under negative pressure and the residue was added to ice. The precipitate (1) was washed with cold water, then filtered off, air dried, and crystallized from chloroform. The compound formation was confirmed with thin-layer chromatography (TLC) chloroform:ethyl acetate (7:3) with Rf value 0.72 with an yield of $64.75 \%$, melting point $57^{\circ} \mathrm{C}$, mol. formula $\mathrm{C}_{6} \mathrm{H}_{6} \mathrm{~N}_{2} \mathrm{O}$, and mol. weight 212.12 .

\section{Step-II: 5-amino-4-cyano-1-phenyl pyrazole}

Ethoxymethylene malononitrile (1) (5.0 g, $40 \mathrm{mmol}$ ), phenylhydrazine $(4.0 \mathrm{ml}, 40 \mathrm{mmol})$, and ethanol $(20.0 \mathrm{ml})$ were taken in a round bottom flask and heated to reflux for $2 \mathrm{~h}$ at $80^{\circ} \mathrm{C}$. The excess ethanol was distilled off from the reaction medium and the residue was added to ice. The precipitate (2) was washed with cold water, then filtered off, air dried, and crystallized from chloroform. The compound formation was confirmed with TLC chloroform:ethyl acetate (7:3) with Rf value 0.54 with an yield of $77.02 \%$, melting point $140^{\circ} \mathrm{C}$, mol. formula $\mathrm{C}_{10} \mathrm{H}_{8} \mathrm{~N}_{4}$, and mol. weight 184.19.

\section{Step-III: “5-amino-1-phenyl pyrazole-4-carboxamide”}

To concentrated sulfuric acid $(40.0 \mathrm{ml})$ in a $1.0 \mathrm{~L}$ beaker, small quantity "of 5-amino-4-cyano-1-phenyl pyrazole" (2) (7.5 g, $40 \mathrm{mmol}$ ) was added with continuous stirring for $2 \mathrm{~h}$. It was then neutralized with dil. sodium hydroxide solution, to $\mathrm{P}_{\mathrm{H}} 7$, under ice-cold condition. "The resulting precipitate" (3) "was filtered off, dried, and crystallized from" chloroform. The compound formation was confirmed with TLC chloroform:ethyl acetate (7:3) with Rf value 0.66 with an yield of $99.64 \%$, melting point $170^{\circ} \mathrm{C}$, mol. formula $\mathrm{C}_{10} \mathrm{H}_{10} \mathrm{~N}_{4} \mathrm{O}$, and mol. weight 202.29.

\section{EVALUATION OF PHARMACOLOGICAL ACTIVITY}

\section{Evaluation of anti-inflammatory activity}

"The lead compounds are screened for anti-inflammatory activity using" the technique "inhibition of albumin denaturation" as per Muzushima and Kabayashi with slight modification as given in Scheme 1. 


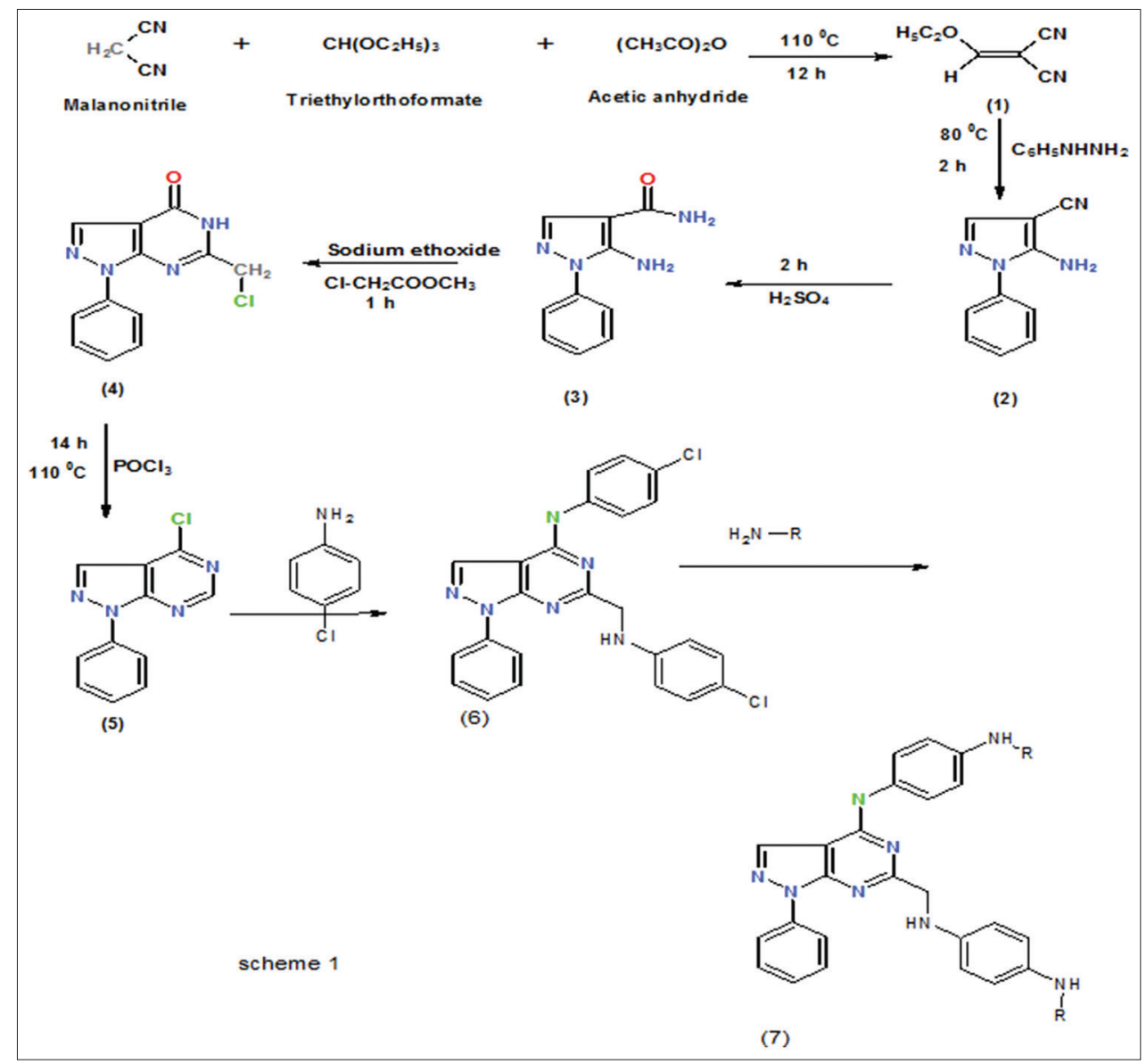

Scheme 1: Synthesis of some novel pyrazole derivatives

\section{EVALUATION OF ANTIOXIDANT ACTIVITY}

Free radicals are reactive atoms that have one or more unpaired electrons, especially one that is produced in the humans as natural biological processes or produced from outside (as in toxins or pollutants and tobacco smoke) "and that can damage cells proteins and DNA by altering their chemical" nature. Free radicals are generally considered as a part of molecules and which are short valid and extremely "reactive." "They are produced" spontaneous "in cells either as accidental by-products of metabolism or deliberately" by "phagocytosis." "Free radicals can be formed in three methods: (1) Hemolytic cleavage of a covalent bond of a normal molecule, each fragment" retains "one of the paired electrons," (2) addition "of a single" from "a normal molecule." and "(3) addition of a single electron to molecule." Later, "electron transfer is a common process in biological systems." The "important free radicals in biological" functions "are radical" derivative "of oxygen." "The" free radical process is a lipid peroxidation plays a radical and causative role in the pathogenesis of cancer, atherosclerosis, and myocardial infarction. Free radical oxidative interactions promote tissue injury in conditions such as toxicity, brain trauma, and ischemia and also in neurodegenerative diseases such as Alzheimer's, dementia, Parkinsonison's disease, and multiple sclerosis are now well documented. "Highly reactive free radicals and oxygen species are present in biological systems from a wide variety of sources." "These free radicals may oxidize" proteins, "nucleic acids," DNA, or "lipids and can initiate degenerative disease." "Antioxidant compounds such as" flavonoids and "polyphenols" which "scavenge free radicals such as peroxide," hydrogen peroxide, or "lipid peroxyl and thus inhibit the oxidative mechanisms that lead to degenerative diseases." "There are a number of clinical studies, suggesting that the antioxidants in fruits, vegetables, tea, and red wine are the main factors for the observed efficacy of these foods in reducing the incidence of chronic diseases including heart disease and some cancers."

\section{ANTIFUNGAL ACTIVITY}

"The" antifungal "activity" of the lead molecules was performed by disc diffusion method which was compared with standard drug fluconazole. It is orally active broad-spectrum antifungal agent.

\section{CONCLUSION}

The present study developed a simple, inexpensive, and facile method for synthesis of pyrazole derivatives in a short duration in mild conditions. All pyrazole derivatives yielded a good outcome of in the range of 60$94 \%$. The purity of the compounds was ascertained by a TLC and melting point. The lead structure was further established by infrared, ${ }^{1} \mathrm{H}$ nuclear magnetic resonance, and MS spectral studies. "Using inhibition of albumin denaturation technique which was studied according to Muzushima and Kabayashi with slight modification the" acute "and" chronic studies for anti-inflammatory activity of the synthesized compounds was screened. In the prepared pyrazole derivatives, it seemed that the compounds ethoxymethylene malononitrile, "5-amino-4-cyano-1-phenyl pyrazole," and 5-amino-1-phenyl pyrazole-4-carboxamide showed potent activity. From the above study, it can be concluded that the pyrazole derivatives are potentially be developed into useful anti0inflammatory agents, which lead to further optimization for producing a novel heterocyclic system, with potent activity.

\section{REFERENCES}

1. Ghorab MM, Ragab FA, Alqasoumi SI, Alafeefy AM, Aboulmagd SA. Synthesis of some new pyrazolo [3,4-d]pyrimidine derivatives of expected anticancer and radioprotective activity. Eur J Med Chem 2010;45:171-8. 
2. Bendich A, Russell PJ, Fox JJ. Synthesis and properties of 6-chloropurine and purine. Am Chem Soc 1954;76:6073-7.

3. Holla BS, Mahalinga M, Karthikeyan MS, Akberali PM, Shetty NS. Synthesis of some novel pyrazolo [3,4-d] pyrimidine derivatives as potential antimicrobial agents. Bioorg Med Chem 2006;14: 2040-7.

4. Bakavoli M, Bagherzadeh G, Vaseghifar M, Shiri A, Pordel M, Mashreghi M, et al. Molecular iodine promoted synthesis of new pyrazolo $[3,4-\mathrm{d}]$ pyrimidine derivatives as potential antibacterial agents. Eur J Med Chem 2010;45:647-50.

5. El-Sherbeny ME. Synthesis and herbicidal activity of novel pyrazolo [3,4-d]pyrimidin-4-oneone derivatives. Arch Pharm 2000;333:99-109.

6. Liu H, Wang HQ, Liu ZJ. Synthesis and herbicidal activity of novel pyrazolo [3,4-d]pyrimidin-4-one derivatives containing aryloxyphenoxypropionate moieties. Bioorg Med Chem Lett 2007;17:2203-9.
7. Quintela JM, Peinador C, González L, Devesa I, Ferrándiz ML, Alcaraz MJ, et al.6-dimethylamino 1H-pyrazolo[3,4-d]pyrimidine derivatives as new inhibitors of inflammatory mediators in intact cells. Bioorg Med Chem 2003;11:863-8.

8. Moukha-Chafiq Q, Taha ML, Lazrek HB, Pannecouque C, Witvrouw M, DeClercq E. Synthesis and anti-HIV activity of new modified 1,2,3-triazole acyclonucleosides. Nucleos Nucleot Nucleic Acids 2002;57:1797-810.

9. Chern JH, Shia KS, Hsu TA, Tai CL, Lee CC, Lee YC, et al. Design, synthesis, and structure-activity relationships of pyrazolo [3,4-d] pyrimidines: A novel class of potent enterovirus inhibitors. Bioorg Med Chem Lett 2004;14:2519-25.

10. Krystof V, Moravcová D, Paprskárová M, Barbier P, Peyrot V, Hlobilková A, et al. Synthesis and biological activity of 8-azapurine and pyrazolo[4,3-d]pyrimidine analogues of myoseverin. Eur J Med Chem 2006;41:1405-11 